\title{
Mortality from dementia in Norway, 1969-83
}

\author{
TROND P FLATEN \\ From the Department of Chemistry, College of Arts and Science, University of Trondheim, N-7055 Dragvoll, \\ Norway.
}

ABSTRACT From 1969 to the end of 1983 in Norway, dementia was coded as the underlying cause of death from 2058 death certificates, and as a contributory cause from 19459 . This is $3.56 \%$ of the total number of deaths. It seems that a considerable proportion of dementia cases are noted on death certificates in Norway. Death rates based on dementia as the underlying cause of death have increased with time, but when including contributory causes, rates have declined. The data may be useful in epidemiological studies, eg, to search for aetiological clues for Alzheimer's disease. Due to the inclusion of contributory causes of death in the registers and to the high number of dementia cases noted on death certificates, Norwegian mortality data on dementia are probably of better quality than in most other countries.

The large public health impact of dementia has only recently been recognised. ${ }^{1-3}$ The cumulative lifetime risk to each individual alive today of becoming severely demented may be as high as $20 \%$ in modern societies. ${ }^{4}$ On this background, epidemiological studies on dementing illnesses are greatly needed. Currently available epidemiological data are still fragmentary, partly at least due to problems of case ascertainment and diagnosis. At this early stage, when we lack reliable data on disease rates in different geographical areas, it would be helpful if readily available data such as those found in central death registers could be used, eg, in preliminary studies of the aetiology of dementing disorders, of which Alzheimer's disease is the most prevalent. ${ }^{256}$

The purpose of the present paper is to describe centrally registered mortality data on dementia in Norway. Contrary to the situation in most other countries, multiple coding of causes of death has been carried out in Norway since 1956. From 1969 onwards, up to three contributory causes of death have been coded per death certificate in addition to the underlying cause. The inclusion of contributory causes probably enhances the usefulness of mortality data on dementia for epidemiological and other purposes.

\section{Methods}

Mortality data (International Classification of Diseases-Eighth Revision (ICD-8) ) were provided by the Central Bureau of Statistics of Norway (CBS) and made available through the research group "Medical Geography in Social Planning" in Trondheim. In
Norway, all death certificates, which are originally filled out by the local medical practitioners, are controlled and coded by the CBS. Most formal errors on the certificates are eliminated by the control procedures. $^{7}$ All death certificates from which dementia was coded either as the underlying or as a contributory cause of death were included in the study. Data concerning underlying cause of death were available up to 1985 , and for contributory causes to 1983.

Age adjusted, sex specific mortality rates were calculated for the individual years 1969-1985 for dementia (ICD-8 290.0 and 290.1 combined) and senility (ICD-8 794) coded as the underlying cause of death. Other conditions which could be related to dementia are ICD-8 299 and 309; in the period 1969-85, 22 deaths were attributed (underlying cause) to "unspecified psychoses" (ICD-8 299), and none to "specific non-psychotic mental disorders following organic brain damage" (ICD-8 309). These numbers are too small to influence the results of the present study significantly, which therefore was restricted to ICD-8 290 and 794. The eighth revision of the ICD has been used in Norway throughout the study period, and there have been no changes in the coding procedures employed by the CBS. For dementia coded either as the underlying or as a contributory cause of death, average annual rates were calculated for the three 5 year periods $1969-73,1974-78$ and 1979-83. The populations at risk were the sex specific populations for the individual years (obtained from the Central Bureau of Statistics); when calculating average rates for the 5 year periods, the mean 
populations for the five individual years were used. Age adjustments were done using the direct method and the total (male plus female) Norwegian population on 1 January 1980 as the standard.

Average annual age and sex specific dementia rates were calculated for seven age groups (45-59, 60-64, $65-69,70-74,75-79,80-84$ and $85+$ years) for the 10 year period 1974-83.

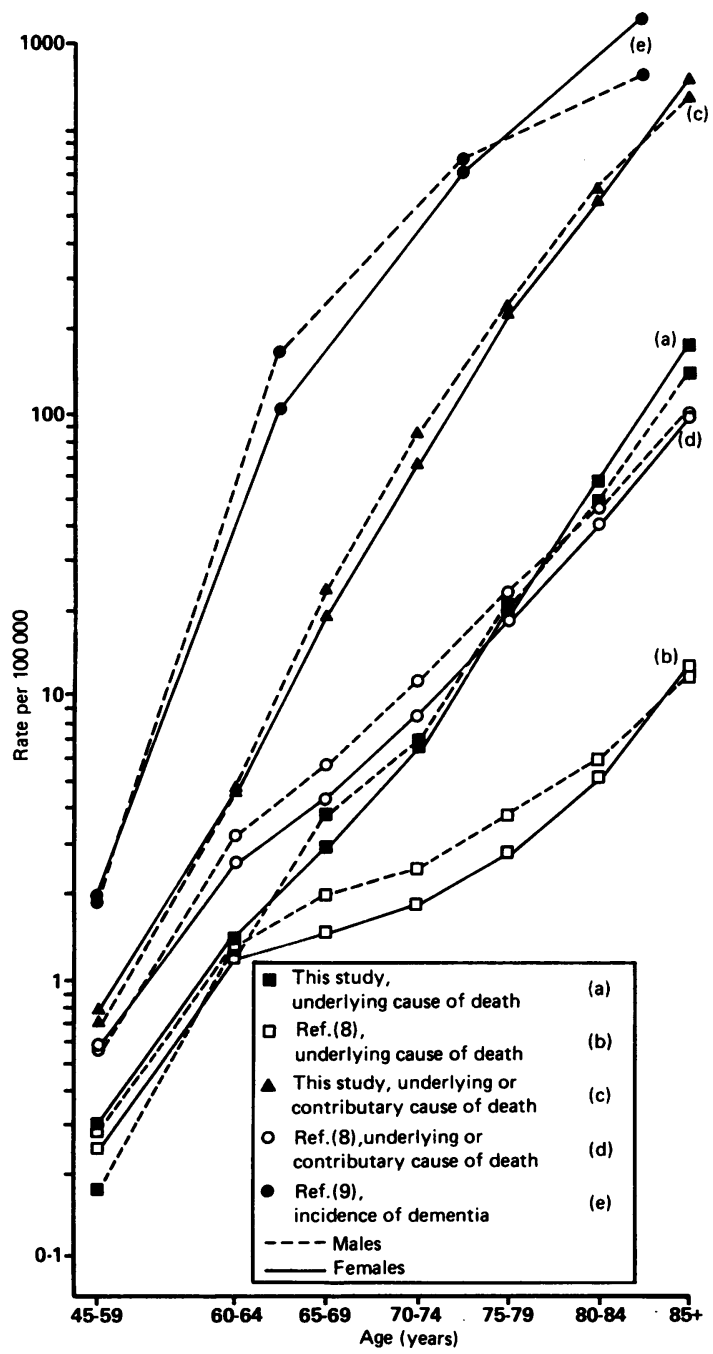

Fig 1 Average annual age and sex specific death rates per 100000 population for dementia in Norway (1974-83, present study) and in the USA (1971 and 1973-78, see $\left.{ }^{8}\right)$, and incidence rates from Rochester, USA $\left(1960-64\right.$, see $\left.^{9}\right)$. Note logarithmic scale on the ordinate.

\section{Results}

In the period 1969-83, dementia was coded as the underlying or a contributory cause of death from 8459 (male) and 13053 (female) death certificates. This is $2.56 \%$ (males) and $4.75 \%$ (females) of the total number of deaths in Norway in this 15 year period. The corresponding numbers for dementia coded as the underlying cause of death are $749(0 \cdot 23 \%$, males $)$ and $1309(0.48 \%$, females). Thus, dementia is coded about 10 times more often as a contributory than as the underlying cause of death.

Average annual age and sex specific mortality rates for the period 1974-83 are given in fig 1, together with
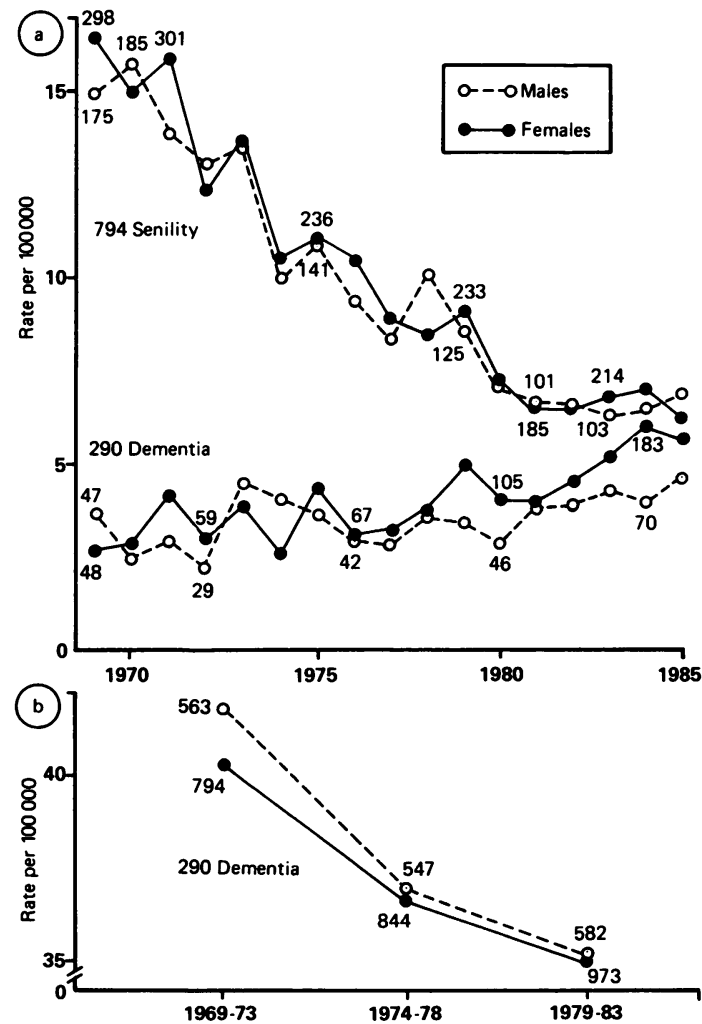

Fig 2 Annual age adjusted death rates per 100000 population for dementia (ICD-8 290.0 and 290.1 combined) and senility (ICD-8 794) in Norway, standardised to the total (male plus female) Norwegian population on 1 January 1980. The numbers beside the data points give the annual numbers of deaths. (a) Annual rates 1969-85 based on the total number of death certificates from which dementia and senility were coded as the underlying cause of death. (b) Average annual rates for three 5 year periods based on the total number of death certificates from which dementia was coded as the underlying or a contributory cause of death. 
mortality rates from a death certificate study in the USA $^{8}$ and incidence rates from Rochester, USA. ${ }^{9}$

Average annual age adjusted mortality rates for the period 1974-83 for dementia coded as the underlying cause of death are 3.6 (males) and 4.0 (females) per 100000 population. When including contributory causes, the rates are $36 \cdot 1$ (males) and 35.8 (females) per 100000 .

The age adjusted mortality rates for dementia coded as the underlying cause of death increased slowly from 1969 to 1985 (fig 2a). The rates for senility declined markedly from above 15 per 100000 around 1970 to about $6-7$ per 100000 in the 1980 s. The number of deaths (males + females) attributed to senility declined from about 470 per year around 1970 to about 300 in 1980-82, but rose again to about 340 in 1984-85. When contributory causes of death are included, both the age adjusted and the age specific dementia rates decline through the three 5 year periods studied (figs $2 b, 3$ ).

The dementia rates are very similar for the two sexes, but tend to be higher for females when considering only the underlying cause of death (figs 1, 2a), and higher for males when including contributory causes (figs 1-3).

\section{Discussion}

In general, studies based on mortality statistics have many limitations, particularly regarding diagnostic accuracy. ${ }^{70-12}$ Even if the deceased person obviously was demented, dementia is not necessarily reported on the death certificate by the local medical practitioner.

Mortality rates reported from the USA are 0.44 (males) and 0.38 (females) per 100000 population for dementia coded as the underlying cause of death, and 2.37 (males) and 2.19 (females) when including contributory causes. ${ }^{8}$ These rates are lower than those of the present study (fig 2) by a factor of 5-20, the difference being larger when including contributory causes than when considering only the underlying cause of death. It is also noted that the increase in mortality rate with age is smaller for the American data (fig 1). The reasons for these differences are not known, but one plausible explanation could be that Norwegian physicians report dementia on the death certificate much more often than their American colleagues do. Other types of studies are required to clarify whether there are differences in the actual incidence or prevalence of dementia between the two countries.

The death rates (fig 2 ) are nearly half the incidence rates of 75.9 (males) and 79.7 (females) found in Rochester, USA, ${ }^{9}$ in a study which probably has the best level of case ascertainment of those published to date. This would seem to indicate that a considerable proportion of dementia cases are noted on death certificates in Norway. However, evidence exists that maybe as many as one person in every five will become severely demented before death. ${ }^{4}$ If this is correct, the notification of dementia on $3.56 \%$ of the death certificates suggests considerable underreporting. Dementia is probably underdiagnosed in the Norwegian population, ${ }^{13}$ but no studies have been

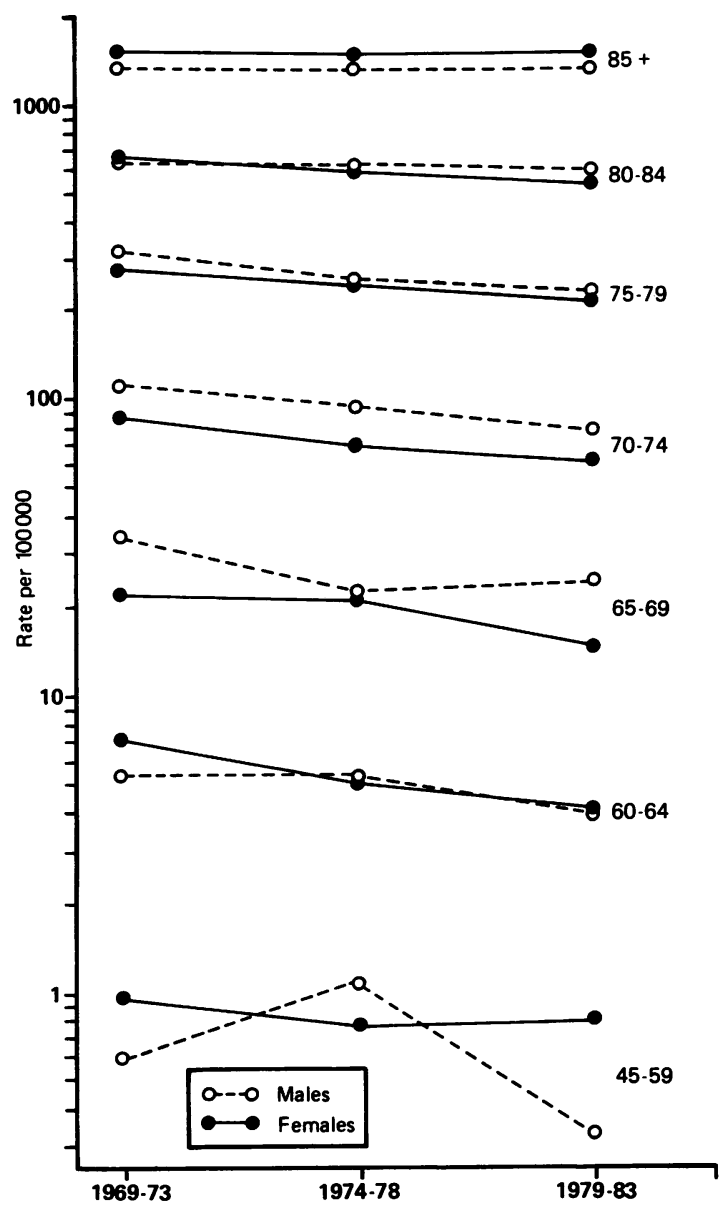

Fig 3 Average annual age and sex specific death rates per 100000 population for dementia for three 5 year periods in Norway. The rates are based on the total number of death certificates from which dementia was coded as the underlying or a contributory cause of death. Note logarithmic scale on the ordinate.

carried out to assess the validity of death certificate data on dementia in this country.

Rates for dementia and senility (underlying cause of death) show opposite time trends (fig 2b). Similar 
trends have been described in other countries, ${ }^{8}$ 14-16 and are probably related to an increased awareness among physicians about dementing illnesses, ${ }^{17} 18$ resulting in reduced use of the less specific term "senility" on death certificates. It should be noted, however, that "senility" is a perfectly acceptable cause of death, in the sense that all tissues age. ${ }^{12}$ An aspect not observed in other studies 81416 is that the decline in senility rates is much steeper than the rise in dementia rates (fig $2 a)$, resulting in a decreasing trend for the two conditions combined.

The decline in rates for dementia coded as the underlying or a contributory cause of death (figs $2 b, 3$ ) is surprising. As a result of greater awareness of dementia as a public health problem in recent years, ${ }^{1-31718}$ increased reporting on death certificates could be expected. The results would seem to indicate that the age specific incidence of dementia is at least not markedly increasing in Norway.

Dementia represents a large and growing burden on victims, relatives and society, ${ }^{1-3}$ and much attention should be paid to identifying risk factors for this major health problem. Dementia can be caused by more than 60 disorders, ${ }^{6}$ with different aetiologies. However, neuropathological studies indicate that Alzheimer's disease accounts for $50-60 \%$ of the total number of dementia cases, and some additional $10-15 \%$ have Alzheimer's disease in combination with multi-infarct dementia. ${ }^{2} 5$ Therefore high quality data on dementia may be useful in epidemiological studies on Alzheimer's disease. ${ }^{4}$

The geographical patterns of dementia mortality reported in England and Wales ${ }^{19}$ and in Norway ${ }^{20} 21$ may well be related to geographical differences in diagnostic facilities, in physician:patient (or neurologist:patient) ratios, in death certification practice, or in the percentage of deaths that have occurred in hospitals. For example, Martyn and Pippard ${ }^{14}$ found a clear coincidence of the locations of large psychiatric hospitals with areas with high dementia mortality, due to the British practice of considering long stay institutions to be the patient's usual address 6 months after his admission. In Norway, the practice is different: if the patient (or his relatives) does not choose to change his place of residence (usually this is not done), he is considered resident of the municipality from which he entered the institution. Therefore the locations of institutions probably do not affect the geographical distribution of dementia mortality in Norway to the same extent as they obviously do in the United Kingdom. In addition, inclusion of contributory causes of death probably gives a higher proportion of less severely demented persons, who are less likely to have died in long stay institutions.

Norway is a country well suited for epidemiological studies, because the population is well registered, $\varnothing$ rather stationary, and socioeconomically and 3 genetically relatively homogeneous. Norwegian mortality data on dementia are probably of better quality than in most other countries, due to the inclusion of contributory causes of death in the $\frac{T}{\mathbb{D}}$

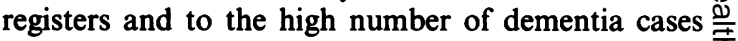
noted on death certificates. Therefore these data might be of value in introductory epidemiological studies, eg, $\overrightarrow{\overrightarrow{\vec{S}}}$ to search for aetiological clues which could be pursued $\underset{\sigma}{\sigma}$ further by in depth research. However, independent assessments of the validity of the mortality data would $\frac{\bar{\sigma}}{\bar{c}}$ be needed before too much trust could be placed in the $\vec{\nabla}$ results. ${ }^{1416}$ Preliminary analysis suggests an $\varrho$ association between dementia and the aluminium of content of drinking water in Norway, ${ }^{20-22}$ and more $\vec{\circ}$ recently similar results have been found in England and Wales. ${ }^{23}$ A Norwegian case-control study using $\vec{\omega}$ mortality data is in progress to investigate this $\frac{\rho}{\circ}$ association further.

I am grateful to Erik Nymoen and Asbjørn Aase $\hat{\omega}$ (University of Trondheim) for help and valuable discussion and for permission to use the mortality dation of base. Thanks are due to Helge Riisøen (Haukelan hospital), Trond Sand (Regionsykehuset, Universi $\vec{F}$ Hospital of Trondheim) and Knut Westlung $\$$ (National Health Screening Service) for they $\frac{\Phi}{0}$ comments on the manuscript.

\section{References}

1 Plum F. Dementia: an approaching epidemic. Nature 1979 279: 372-3

${ }^{2}$ Katzman R. Alzheimer's disease. N Engl J Med 1986; 314: 964-73.

${ }^{3}$ Ineichen B. Measuring the rising tide: how many dementia cases will there be by 2001 ? Br J Psychiatry 1987; 150: 응 193-200.

${ }^{4}$ Mortimer JA, Schuman LM, French LR. Epidemiology of $\stackrel{2}{\overrightarrow{7}}$ dementing illness. In: Mortimer JA, Schuman LM, eds. 음 The epidemiology of dementia. Oxford: Oxford University 3 Press, 1981: 3-23.

5 Tomlinson BE, Blessed G, Roth M. Observations on the brains of demented old people. J Neurol Sci 1970; 11: 205-42.

${ }^{6}$ Haase GR. Diseases presenting as dementia. In: Wells CE, 号 ed. Dementia. 2nd ed. Philadelphia: F. A. Davis, 1977: 27-67.

${ }^{7}$ Glattre E, Blix E. Evaluation of the cause-of-death statistics. Oslo: Central Bureau of Statistics of Norway, 1980; Report no 80/13.

${ }^{8}$ Chandra V, Bharucha NE, Schoenberg BS. Patterns of 0 mortality from types of dementia in the United States, 1971 and 1973-1978. Neurology 1986; 36: 204-8.

${ }^{9}$ Schoenberg BS, Kokmen E, Okazaki H. Alzheimer's disease and other dementing illnesses in a defined United States population: incidence rates and clinical features. ON

Ann Neurol 1987; 22: 724-9.
${ }_{10}$ Hartveit F. Clinical and postmortem assessment of the cause of death. J Pathol 1977; 123: 193-210. 
11 The Royal College of Physicians and the Royal College of Pathologists. Medical aspects of death certification. $J \boldsymbol{R}$ Coll Physicians Lond 1982; 16: 206-18.

$12 \mathrm{Knight}$ B. The cause of death (Editorial). J $R$ Soc Med 1986; 79: 191-2.

${ }^{13}$ Nygaard HA. Senil demens: en underdiagnostisert tilstand? Betydning for situasjonen i somatiske sykehjem. Tidsskr Nor Laegeforen 1985; 105: 351-2.

14 Martyn CN, Pippard EC. Usefulness of mortality data in determining the geography and time trends of dementia. $J$ Epidemiol Community Health 1988; 42: 134-7.

15 Newman SC, Bland RC. Canadian trends in mortality from mental disorders, 1965-1983. Acta Psychiatr Scand 1987; 76: 1-7.

16 Jorm AF, Henderson AS, Jacomb PA. Regional differences in mortality from dementia in Australia: an analysis of death certificate data. Acta Psychiatr Scand 1989; 79: 179-85.

${ }^{17}$ Rubin SM, Glasser ML, Werckle MA. The examination of Physicians' awareness of dementing disorders. $\mathrm{J} \mathrm{Am}$ Geriatr Soc 1987; 35: 1051-8.

18 O'Connor DW, Pollitt PA, Hyde JB, Brook CPB, Reiss BB, Roth M. Do general practitioners miss dementia in elderly patients? Br Med J 1988; 297: 1107-10.
${ }^{19}$ Gardner MJ, Winter PD, Barker DJP. Atlas of mortality from selected diseases in England and Wales 1968-1978. Chichester: Wiley, 1984.

${ }^{20}$ Flaten TP. An investigation of the chemical composition of Norwegian drinking water and its possible relationships with the epidemiology of some diseases Trondheim, Norway: University of Trondheim, 1986. 272 pp. Thesis.

${ }^{21}$ Flaten TP. Geographical associations between aluminium in drinking water and death rates with dementia (including Alzheimer's disease), Parkinson's disease and amyotrophic lateral sclerosis in Norway. Environ Geochem Health 1989 (in press).

22 Vogt T. Water quality and health-study of a possible relation between aluminium in drinking water and dementia (English abstract). Oslo: Central Bureau of Statistics of Norway, 1986; Sosiale og økonomiske studier no 61.

${ }^{23}$ Martyn CN, Osmond C, Edwardson JA, Barker DJP, Harris EC, Lacey RF. Geographical relation between Alzheimer's disease and aluminium in drinking water. Lancet 1989; i: 59-62.

Accepted for publication March 1989 